\title{
The Social Network: How People with Visual Impairment use Mobile Phones in Kibera, Kenya
}

\author{
Giulia Barbareschi*1, Catherine Holloway*1, Katherine Arnold ${ }^{1}$, Grace Magomere ${ }^{2}$, Wycliffe \\ Ambeyi Wetende ${ }^{2}$, Gabriel Ngare ${ }^{2}$, Joyce Olenja ${ }^{2}$ \\ *Joint first author \\ ${ }^{1}$ London, UK, \{giulia.barbareschi.14, c.holloway, katherine.arnold.15\} @ucl.ac.uk \\ ${ }^{2}$ Nairobi, Kenya, \{gmagomere, mzungureload77, gabrielngare253, jolenja\} @ gmail.com
}

\begin{abstract}
Living in an informal settlement with a visual impairment can be very challenging resulting in social exclusion. Mobile phones have been shown to be hugely beneficial to people with sight loss in formal and high-income settings. However, little is known about whether these results hold true for people with visual impairment (VIPs) in informal settlements. We present the findings of a case study of mobile technology use by VIPs in Kibera, an informal settlement in Nairobi. We used contextual interviews, ethnographic observations and a co-design workshop to explore how VIPs use mobile phones in their daily lives, and how this use influences the social infrastructure of VIPs. Our findings suggest that mobile technology supports and shapes the creation of social infrastructure. However, this is only made possible through the existing support networks of the VIPs, which are mediated through four types of interaction: direct, supported, dependent and restricted.
\end{abstract}

\section{Author Keywords}

Accessibility; HCI4D; ICT4D; Participatory Design; Kenya, Kibera; Informal Settlements

\section{CSS Concepts}

- Human-centered computing • Accessibility • Empirical studies in accessibility

\section{INTRODUCTION}

People with visual impairment encounter numerous challenges in their daily lives that can limit access to basic services resulting in loss of participation in society [69]. Generally, a lack of accessibility within transport, healthcare, education or employment create economic and practical issues for both people with disabilities (PWDs) and society as a whole. Furthermore, this lack of accessibility creates conditions for social exclusion, which has been shown to lead to short- and long-term psychosocial damage for PWDs [64]. In low- and-middle-income countries (LMICs), where $80 \%$ of PWDs live, these challenges are often more

Permission to make digital or hard copies of all or part of this work for personal or classroom use is granted without fee provided that copies are not made or distributed for profit or commercial advantage and that copies bear this notice and the full citation on the first page. Copyrights for components of this work owned by others than ACM must be honored. Abstracting with credit is permitted. To copy otherwise, or republish, to post on servers or to redistribute to lists, requires prior specific permission and/or a fee. Request permissions from permissions@acm.org.

CHI '20, April 25-30, 2020, Honolulu, HI, USA.

(C) 2020 Association for Computing Machinery.

ACM ISBN 978-1-4503-6708-0/20/04 ...\$15.00

DOI: http://dx.doi.org/10.1145/XXXXXXX.XXXXXXX** prominent due to the lack of access to essential assistive technology (AT) , societal stigma, inadequate policy frameworks and an inaccessible physical environment $[28,39,74]$.

Technologies such as mobile phones increase independence and social participation of PWDs [43]. Mobile technology is important as it can function both as a social enabler and a "traditional" AT [16]. In high-income contexts, the modern smartphones with built-in screen readers have opened-up new levels of possibilities for VIPs [15]. Additionally, HCI researchers have helped to develop new ways of identifying objects [29], aided better city navigation [56] and helped to create more inclusive education experiences [37] - all driven by smartphone technology. Mobile can thus be seen, within these contexts, as a key enabler for VIPs. Indeed, the WHO has included mobile phones (with accessible technology) on the Priority Assistive Products List [4] - a list that contains assistive products deemed essential for fulfilment of the Sustainable Development Goals.

In LMICs mobile phones have also bucked the trend for technology diffusion more generally. Unlike infrastructurally heavy technologies, like computers, which have a penetration rate of $25 \%$ in LMICs [79], the mobile diffusion rate is estimated to be $91 \%$ in Kenya [80]. This represents an opportunity for more inclusive societies. However, smartphone ownership, which offers most potential to VIPs, is estimated to be only $30 \%$ in Kenya [42]. The remaining $61 \%$ of phones are feature or basic phones. Feature phones with screen readers can have a positive impact on VIPs living in LMICs. However, they do not offer the same possibilities for accessibility as smartphones; furthermore, basic phones do not have any type of screen reader making accessibility challenging $[43,44]$.

In LMICs previous research has found mobile phones are not always used directly by the owner. Instead, the mobile offers a gateway to services, through both direct and intermediated (i.e. with the help of another person) use. Intermediated use of technology has been found when examining the social infrastructures which support technology use within the field of ICT for Development (ICT4D). Examining social infrastructures is often accomplished through the lens of human infrastructure, which allows the complex sociotechnical infrastructures to be captured and analyzed. 
Within LMICs, informal settlements (sometimes referred to as "slums") represent a particular urban ecosystem with specific organizational, societal and infrastructural characteristics. However, we know very little about how human infrastructuring affects the lives of PWDs who live in these communities. Specifically, we are unclear on how the social infrastructure affects the way VIPs access mobile phones and other digital technologies and what affect use has on their daily lives and ability to participate in society. In this paper we contribute:

- The first case study which explores mobile phone interactions among VIPs living in informal settlements;

- The identification of four types of mobile phone interaction: restricted, supported, dependent, independent by VIPs in Kibera;

- The exploration of the future interactions VIPs in Kibera aspire to have, which resulted in unrestricted interactions for future VIPs alongside increased numbers of social interactions.

\section{RELATED WORK}

\section{Informal Settlements}

Informal settlements are unplanned settlements usually located in peri-urban areas of many large cities in LMICs. From a social-economic point of view, informal settlements combine elements of urban and rural communities and are often characterized by poverty and scarcity of services compared to formal urban settlements [6]. The conditions found in informal settlements are known to impact negatively on the quality of life of residents [78]. The physical environment - open latrines, irregular building lines and uneven ground - all make navigation difficult. Digital infrastructure is also challenging - electricity, where it is available, is often 'tapped' illegally from main lines and is therefore unreliable. On the positive side, informal settlements have reduced social constraints, allowing for the creation of wider and more dynamic social support systems which influence how people interact with each other [68]. Furthermore, informal settlements are characterized by ever changing circumstances (including casual working arrangements and non-permanent housing) which can cause residents to be more resilient and less fearful of change which might reflect in their attitudes towards mobile technology [76].

Although little is known about the everyday challenges that VIPs who live in informal settlements face, it is clear that practical challenges such as overcrowding, unpaved and uneven roads could make independent navigation extremely difficult with subsequent negative impact on employment and education. VIPs are also potentially more vulnerable to fraud, mugging and other forms of robbery which are notoriously common in many informal settlements [59]. On the other hand, VIPS might experience increased opportunities due to reduced stigma in informal settlements compared with rural settings due to the more progressive attitude which characterize informal settlements.
Kibera is possibly the most researched slum in the world, with countless projects that have covered topics from sanitation [53] to the social impact of internet cafes [71]. Despite the wide number of studies, little is known about the everyday lives of PWDs in Kibera. For example, the benefits, implications and challenges of mobile phone ownership and internet access among Kibera's youth was previously investigated [33]. The study found mobile phones were considered prized possessions that enabled connection to others and self-expression. However, social stigma attached to residency in Kibera was a concern when interacting with others on social media. Unfortunately, no similar studies involving VIPs or PWDs in general exists.

\section{VIPs and Mobile Phones}

Mobile phones can provide great opportunities for empowerment for many VIPs [26]. Mobile phone research for VIPs, which is often focused in high income settings and on the smartphone, has explored issues as diverse as: navigation [1], obstacle avoidance [32], phone accessibility [34], object recognition [29] and activities of daily living [55]. Research within LMICs has focused on low-cost innovations such as Audioguide which supports navigation of VIPs who use low cost feature phones in Brazil [19] and a free, voice-based social media platform for blind people in India [70].

Regardless of setting, mobile phone adoption by VIPs is a complex issue which encompasses elements of the network, the handset and the person's capabilities to use the interface and features of the phone [45]. Moving from a button interface to a touchscreen is daunting $[12,48]$. The steep learning curve necessitates the use of the old button phone and the new smartphone during a transition period $[45,48]$ which lasts for 9 months on average [45]. Although the transition was difficult, once adopted the smartphone was found to enable people to explore a wide range of things from social media use to language learning [12].

In a more recent study across VIPs in Bangalore and Seoul it was found that whilst phone use increased with smartphone adoption, the accessibility of the mobile phone ecosystem affected how the smartphone was used [45]. For example, the smartphone was often desired to overcome navigation issues of the cities, and to allow greater access to social media. However, having overcome the fear of switching from a button interface, and learning to use their smartphone, many users found that the most-desired function - GPS enabled navigation - was inaccessible due to usability failures in the network, handset hardware limitation or user-interface failures [45]. The study also found that, without a button interface, VIPs consumed more social media but created far less content. Other factors such as gender, social economic status, physical accessibility of a city and social attitudes affect how VIPs adopt mobile phones into their lives [48].

\section{Social \& Human Infrastructure}

Accessibility research has in recent years taken a 'turn to the social' [23,49]. In doing so new approaches to how we 
explore the interaction between disabled people and technology have emerged. Ability-based design for example moves beyond looking at ability deficits to one which designs for what people can do [73]. It takes into account not only the interaction of the person using a technology, but the system in which the technology operates, which is often the root cause of the disability. This approach champions designing for context to ensure systems are more usable to more people. The Disability Interaction (DIX) manifesto complements Ability-based design [27]. DIX looks to use user-centered design with disabled people to build new knowledge which lead to mission-statements and challengebased design at a global scale; demanding the systems-level to be more accessible from the start and therefore reducing the amount of user-based adaptations which are so often necessary (as found by Kane et al. [31] for example).

This move to embrace the social brings a natural overlap with the concept of Human infrastructure. Human infrastructure describes the rich social systems in which technologies are used within resource-poor environments [26]. Such a system combines human actors, relationships, activities, spaces, networks and goals. These systems outlive any attempted technological intervention [26]. However, the human infrastructure can also serve to amplify the possible outcomes of technology use [66]. The Technology Amplification Theory [67] demonstrates that technology alone is not capable of directing change. Instead, technology can only amplify the direction of travel of a society - it can make things worse as well as better. This is important given development has been found to increase the inequality gap for disabled people [41].

The nature of human infrastructure gives rise to a number of user types in LMICs. These include 'direct' [51], 'intermediary' [51] and 'beneficiary' users [63]. Direct use occurs when the primary user directly uses a technology, they own to complete a task. Intermediary users can: 1) use technology on behalf of a request from the direct user (surrogate usage); 2) can enable the direct user to use the technology themselves (proximate enabling), or 3) can support the user by simplifying the interface or information output of the technology (proximate translation) [51]. The term beneficiary user is used to describe the primary-user when their technology use is mediated by an intermediaryuser [22,51]. Intermediary users take the form of a 'fundamental enabler' within the interaction context [51]. Intermediated interactions also have the effect of expanding the use of a technology beyond that of the user interface, to one that includes the participation of the beneficiary user [51] and in doing so enhance a person's capabilities as defined by Sen [54].

Social interactions have specific importance for AT use. For example, within both social and employment settings Pal et al. [57] found AT use by VIPs drove social interactions. However, within the lived experiences of VIPs they identified many occasions where AT was insufficient in enabling independence and as such contributed to dependent interactions occurring [57]. This type of dependence contributes to misperceptions of what an AT user is and isn't capable of. People, incorrectly assume the AT has in some way eliminated a person's disability or that without the AT the user is unable to do anything [57]. AT is simply a tool for capability enhancement; it neither eliminates a person's disability, nor provides all of a person's functions. AT therefore is important in shaping the 'ability negotiations' of PWDs, which are inherently part of the social fabric of life [65]. To address this, Shinohara and Wobbrock argue for a new design approach for technologies used by PWDs design for social acceptance [57]. This new approach applies equally to AT and mainstream technologies [57] such as mobile phones.

To date, there are not any studies that look specifically at use of mobile technology by VIPs in informal settlements. This study builds upon work by $[44,51,52]$ and contributes a case study and a deep understanding of how VIPs in Kibera use mobile phones and how the mechanisms within their social infrastructures create unique types of interactions.

\section{METHOD}

The aim of this study was to explore how VIPs in Kibera interacted with technology in their everyday lives and how the current interactions they had matched their future life aspirations. To this end, we formulated two stages of research. First, we carried out a series of contextual semistructured interviews and ethnographic observations with VIPs. These were conducted to identify the types of interactions participants had when using mobile phones for different purposes, and to understand how these interactions are characterized by their social components. Building on the initial findings from the interviews and observations we developed two activities for a co-design workshop. The workshop aimed to explore how participants aspired to interact with technology and their social environment in the future, and the role they envisioned these interactions could take in achieving more fulfilling lives.

From Participatory to a Hand-Over Research Framework The purpose of this work was to understand current technology interactions and generate ideas for contextually appropriate technologies that are in line with the social and cultural practices of VIPs living in Kenyan informal settlements. Our approach extends prior work which considers both the social and material context of accessibility such as [65]. This project is part of a much wider program of work, which has just started called AT2030 (www.AT2030.org) and, as part of this, we wished to be able to explore the boundaries between a participatory and a hand-over approach [50] to research within the setting of Kibera. We started with a participatory base, then worked with the local organizations to identify two people who would be interested in joining the research team as community researchers. This approach was taken to: mitigate against potential "cultural collision" of conducting $\mathrm{HCI}$ 
research in the Global South [14]; generate research that is emancipatory and not exploitative [63]; extend the reach of the study in terms of access to participants; attempt to 'give back' through the research process itself [61] and because involving community members has been shown to improve the quality of the research [38].

The research protocol was designed in collaboration between University College London, University of Nairobi and the Kilimanjaro Blind Trust a local DPO that actively supports VIPs in Kenya. It was approved by the UCL (ref: 1106/014) and the University of Nairobi (ref: KHN-ERC/A/323) ethical committees. The research team in the field then, comprised traditional academic researchers alongside community researchers. The interviews and ethnographic observations were conducted by the academic researchers with the support of the community mobilizer who was also a VIP. Photographic data collection was carried out (almost entirely) by the Kibera resident research guide who was shown how to use the camera and was instructed on the ethical aspects of taking pictures in community settings [72]. Once participants had expressed informed consent, the guide/researcher took photos during interviews and field observations, paying attention to when participants wanted something captured. Informed consent was gained from all participants at the start of each research session, this process was led by the community mobilizer.

\section{Contextual interviews and field observations}

\section{Participants}

Six visually impaired participants took part in contextual semi-structured interviews and field observations ( 3 female, 3 male, aged $28-65$ years, Median $=36.5$ years $)-$ see Table 1 for details. All participants owned a mobile phone and lived in Kibera from between 6 and 46 years (See Figure 1).

\section{Materials}

Interviews and field observations were recorded with a portable audio recorder and lapel microphone. A back-up recording was made in parallel with a second audio recorder. An Apeman camera and a mobile phone were used to capture photographs and video. Hand-written field notes were also used to record data at the end of each day.

\section{Procedure}

Participants were purposefully recruited by the local DPO according to the inclusion criteria (VIP, resident in Kibera, age over 18 and mobile phone owner). Interviews were carried out in English or Kiswahili according to the preferences of the participant.

During the interviews, participants were asked questions that covered different areas of interest including demographics, length of time lived in Kibera, things they like and dislike about living in Kibera, typical daily activities and ownership of technology including mobile. This was complemented by a tour of their mobile phone. Participants were then asked to describe typical activities that they did with a mobile phone, with particular attention placed on barriers encountered during the interaction with the mobile phone and the potential role of any third-party during use.

\begin{tabular}{|c|c|c|c|c|}
\hline & $\begin{array}{c}\text { Visual } \\
\text { Impairment }\end{array}$ & Age & Gender & $\begin{array}{c}\text { Type of } \\
\text { mobile phone }\end{array}$ \\
\hline 1 & Partial sight & 68 & $\mathrm{M}$ & Smartphone \\
\hline 2 & Partial sight & 28 & $\mathrm{~F}$ & Feature phone \\
\hline 3 & Partial sight & 31 & $\mathrm{~F}$ & Feature phone \\
\hline 4 & Blind & 49 & $\mathrm{M}$ & Basic phone \\
\hline 5 & Blind & 41 & $\mathrm{M}$ & Feature phone \\
\hline 6 & Blind & 32 & $\mathrm{~F}$ & Feature phone \\
\hline
\end{tabular}

Table 1. Demographic characteristics and type of mobile phone owned by participants taking part in semi structured interviews and ethnographic observations

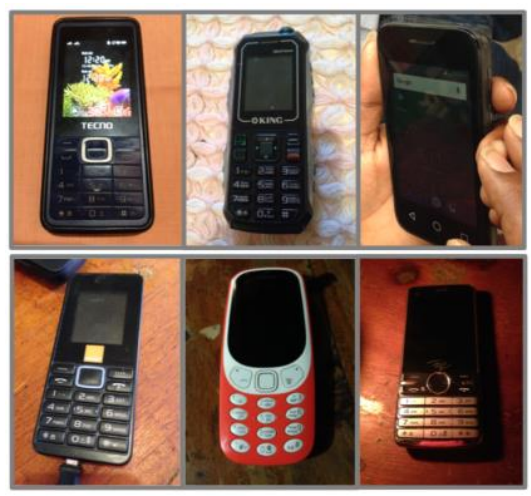

Figure 1: Mobile phones used by interviewed participants

During ethnographic observations, participants demonstrated how they used their mobile phone inside and outside of their home for everyday purposes related to their personal and working lives. Attention was also paid to the use of other technologies and any interaction that occurred with relevant members of the human infrastructure of the participants. Short unstructured interviews were carried out with these technology supporters to further explore the different interactions. Informed consent for these unstructured interviews was gathered verbally before data was recorded.

\section{Co-design}

Following the interviews, a co-design workshop was held to explore future interactions which might be possible for VIPs living in informal settlements.

\section{Participants}

Ten participants took part in a co-design workshop ( 7 female, 3 male) - one of these had also taken part in interviews/observation. Participants had a wide range of visual impairments, literacy, and language - see Table 2 for details. All participants owned a mobile phone and lived in an informal settlement in Nairobi, Kenya.

\section{Design}

The co-design workshop used participatory design methods explicitly because they have been shown to give power and 
agency to participants and are understood to support sustainable collaboration in Africa [10,47]. This approach has also been shown to contribute to the well-being and selfesteem of participants in studies with PWDs in similar contexts $[36,40]$.

\begin{tabular}{|c|c|c|c|}
\hline & $\begin{array}{c}\text { Visual } \\
\text { Impairment }\end{array}$ & Literacy & Language \\
\hline 1 & Partial sight & Large Print & Kiswahili/English \\
\hline 2 & Partial sight & Large Print & Kiswahili/English \\
\hline 3 & Partial sight & Print or Braille & Kiswahili/English \\
\hline 4 & Blind & Braille grade 2 & Kiswahili/English \\
\hline 5 & Partial sight & Large Print & Kiswahili/English \\
\hline 6 & Partial sight & Large Print & Kiswahili/English \\
\hline 7 & Partial sight & Large Print & Kiswahili \\
\hline 8 & Blind & Illiterate & Kiswahili \\
\hline 9 & Blind & Illiterate & Kiswahili \\
\hline 10 & Blind & Braille grade 2 & Kiswahili/English \\
\hline
\end{tabular}

Table 2. Visual impairment, literacy and preferred language of all participants in the co-design workshop.

Storytelling was chosen as a non-confrontational activity $[35,63]$ appropriate to the African cultural context [47], which was accessible to visually impaired and/or illiterate participants. Social acceptance, independence and community support networks all emerged as key themes during the first phase of the research. These were then used to create the beginning of a narrative plot, which we used to draw out participants' aspirations and hopes for the future alongside the possible roles for technology. Modelling to produce 'speculative designs' [17] is known as a method which creates ideas as well as physical things, and also works well with participants in low-income settings [75]. We therefore adopted this.

\section{Materials}

Audio and video data were gathered with the same modalities illustrated for the first study. Three braille machines, marker pens and sheets of paper were available during the storytelling exercise. Re-usable modelling clay, colored card, pens, stickers and craft materials were provided for the modelling exercise. The wide variety and bright colors were chosen to make the exercise as accessible as possible. The research team developed instructions for each narrative in both print and braille.

\section{Procedure}

As with the previous study, participants were purposefully recruited by the local DPO according to the inclusion criteria (VIP, resident in an informal settlement in Nairobi, age over 18 and mobile phone owner). Informed consent was gained from all participants at the beginning of the workshop.
In the storytelling activity, participants were divided into groups of three people. The community mobilizer read the narrative out loud (see Figure 2). The groups were then asked to complete their own fictional stories. Each group had a facilitator from the research team whose role was to support and involve the entire group. At the end of the exercise a volunteer from each group read out their story to all the other participants. In the modelling activity the groups were asked to produce designs for technology that could support independent lives and present to the rest of the group a scenario in which the technology would be used in the future. Each activity was followed by a facilitated group discussion about the stories and designs that had been produced.

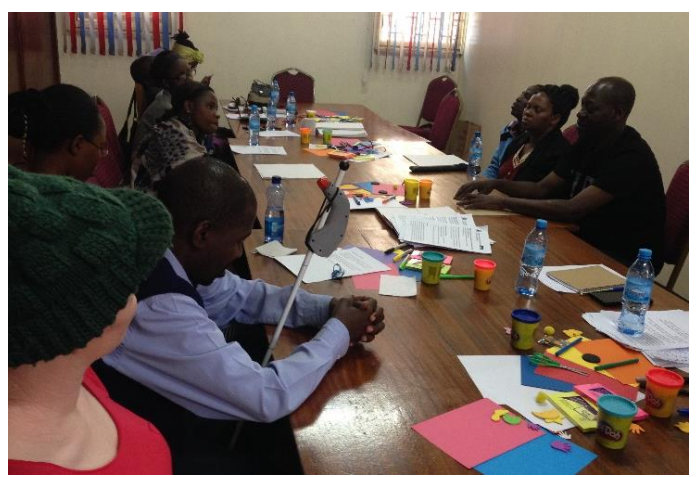

Figure 2. The community mobilizer reads aloud the braille version of the narrative for one of the storytelling exercises during the co-design workshop

\section{Analysis}

All participants' interview data was transcribed verbatim and then translated into English where necessary. Thematic Analysis [9] was used to analyze the qualitative data generated in the interviews and field observation data audio, photos, transcripts and videos - and all co-design data - audio, photos, videos, handwritten stories. Data were initially coded separately by two academic researcher and when patterns emerged these were discussed with the whole research team to ensure that the interpretation of the findings was both accurate and culturally appropriate.

Data from the interviews and ethnographic observations were coded using a hybrid deductive and inductive approach [18]. Initially, we proposed to match interactions according to the framework proposed by Sambasivan et al. [51]. However, as the analysis progressed the interaction types were reframed under four categories that build on the intermediary user types identified by Sambasivan et al. (we propose supported and dependent interactions) and introduce restricted interactions. Sub-themes in each category were coded inductively until saturation. Data from the co-design workshop were coded according to the same framework of interaction categories that emerged from the first study. As data were progressively coded, we noticed that only two of the previously identified interactions were present in the future scenarios and a third new category emerged (un)restricted interactions. 


\section{STUDY1 RESULTS: INTERACTION TYPES}

From the first study we identified four types of interactions that the participants had when using their mobile phone: supported interaction, direct interaction, dependent interaction and restricted interaction. As shown in Figure 3, each interaction has an identified characteristic which was found to be the core value that defines the interaction type.

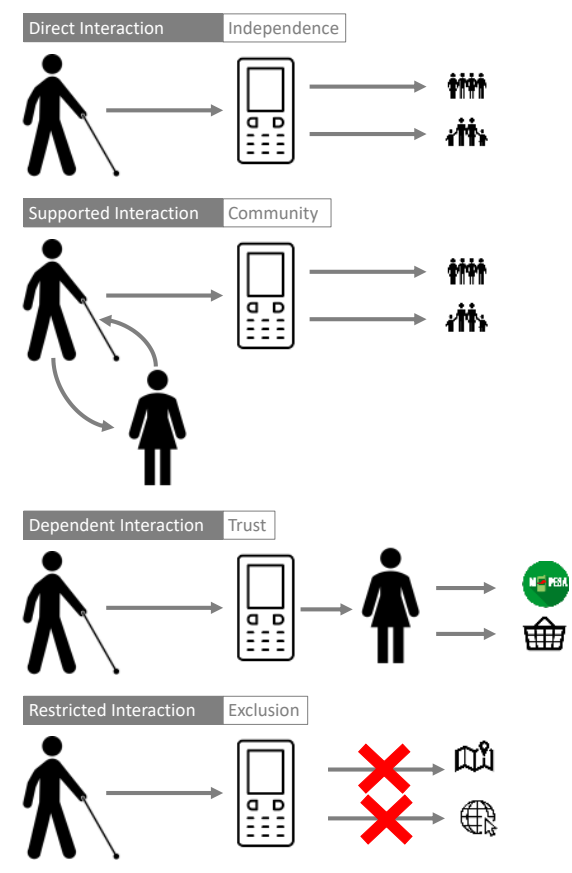

Figure 3. Illustration of the four interaction types identified in Study 1 (see main text for details of each interaction type).

\section{Direct Interactions}

Direct Interactions were categorized by independent mobile use by the VIP. Although these direct interactions were mainly described in relation to mobile phones, they went beyond the use of mobile phones as people spoke more generally about interacting with basic appliances e.g. kettles and radios. Direct interactions with mobile phones were facilitated by physical buttons on feature and basic phones. On the smartphone, basic use was normally facilitated through a screen reader but $\mathrm{P} 01$ who received a smartphone from a local charity but without training on how to operate it found direct use difficult, though he continued to interact in this way. He explained: "I used to have another one, which was talking also but it had some keys and I could go anywhere I want but this one is more difficult because it has no buttons and sometimes it is even disturbing other people because of this talking back" [P01, Interview].

All participants demonstrated the ability to use basic functions independently on their mobile phone - turn the phone on and off and receive or make a call. However, most participants struggled to navigate their contact lists and relied on remembering key phone numbers or simply typing in a number that was dictated to them: "So if I want to make a call for instance, just tell me your number ... then I press call.
Yes, it is calling now. So that is how I operate.... I have to have it [a person's number] in my head." [P05, Interview].

Only two partially sighted participants were able to search through their phone's list of contacts by using the keypad to type in the name they were looking for. In general, direct interactions were mainly used to keep in contact with close personal relationships, as well as making essential calls ("When I want to go places and I lose the way I just call" [P03, Interview]).

\section{Restricted Interactions}

Restricted interactions are ones which are unavailable to the user. These were mainly caused by one of four factors:

Cost of the service: None of the participants used the Internet, despite three phones being able to do so due to the cost of mobile data, as expressed by P03: "I know it [this phone] can go to the internet but I have never allowed anybody to go to the internet with it because it will cost me money" [P03, Interview].

Hardware Limitations: Hardware limitations Smartphones were desired by participants. However, the one smartphone user [P01] we interviewed expressed frustration with his device. Despite the accessibility features of the smartphone, the lack of a physical interface restricted his ability to use certain mobile services. Hardware limitations also restricted interactions for basic functions, for example, P03 and P05 wanted to use the camera on the phone but couldn't due to lack of storage.

Accessibility features: Most [P02, P03, P04, P06] of the participant's phones lacked basic accessibility features such as screen readers_which prevented them from reading SMS.

Digital Skills \& Knowledge: despite a keenness to explore technology, many remained unable to operate their phone to its full potential due to a lack of device-specific digital skills. For example, P05 was the only feature phone user with a screen reader, which would have made his phonebook accessible to him. However, he believed "phonebook and other things those are the ones which I don't operate, because it is not for persons living with visual impairment [P05, Interview]. In the case of P01, despite knowledge of the features on the handset ("There is internet, there is everything in this phone, and it can talk" [P01, Interview]) and a willingness to try and explore the device themselves ("it is my own thinking to do what I hear" [P01, Interview]) the participant was unable to access the Internet or messages. He expressed the desire for a "guide" to help him navigate the device so that over time he could become more independent using his mobile phone.

Many people mentioned a utopic "blind phone", for example: "I was wishing to get a phone that I just operate myself. It is too expensive - the blind phones. Yes, I hope to get one." [P05]). The main driver was to access the Internet. There was no mention of using the phone as a navigation tool. This might seem a natural result of feature phone use 
which don't have access to navigation tools. However, we feel it is worth mentioning as all participants struggled with the physical infrastructure, for example: "There are open trenches they are passing just by the door, so you can imagine a person living with a disability, sometimes as you move you think you have avoided them instead you end up even tripping and falling in them" [P06, Interview]. Within high-income contexts navigation is a common usage of mobile phones for VIPs. So, we include the lack of navigation awareness as a restricted interaction here by its absence in description. It was interesting that technology to aid navigation was one of the themes which emerged from our co-design session.

Regardless of the cause of the restriction, restricted interactions resulted in the social exclusion of the VIP user, often generating feelings of frustration or disempowerment.

\section{Supported Interactions}

Supported interactions took two forms, supported by two elements of the VIP's social network.

Family \& Neighbors: Some participants lived with or had family nearby who would be called upon to provide support with mobile phone use: "I can just ask them. There are many outside there and they know I have that problem." [P02, Interview]. The close-knit structure of Kibera - both physically and socially - meant family and neighbors were often called upon to help with these tasks. They would put numbers in phone contact lists, read and reply to text messages and check airtime credit.

Specific support person: Most of the VIPs interviewed had identified a specific someone in their network that they went to for technology advice and support. These relationships were often very important to the participants - ("The guy who taught me how to use the phone is the one who enlightened me on everything." [P06, Interview]). These interactions meant that participants were confident to explore and experiment with their phones knowing that things could be rectified if things went wrong. "He teaches youths about computers... so if I have a problem with my phone, I take it to him and he helps me." [P03, Interview]).

The key enabling factor for supported interactions was the fact that the supporters were part of the social community of the participant. The presence of a personal bond made participants feel at ease and enabled them to ask for support without feeling in debt. Interestingly, these supportive characters were often found to be a point of reference not only for the participant but for other people in the family or neighborhood. For example, one of P03's friends who often helped her when she needed to read or type SMS, stated that she often helps other women in the neighborhood when they wanted to learn to use some mobile services that they were unfamiliar with. As much as participants felt able to ask for the help of these tech supporters freely, the shared sense of community made tech supporter feel like their help was never onerous but simply part of their friendship bond.
Dependent Interactions

Dependent interactions were characterized by a person who was not the primary user - usually a shopkeeper - directly using the phone interface on behalf of the VIP - See Figure 4. M-Pesa mobile money transfer and financing system is a special case of mobile phone. When receiving help from the M-Pesa (mobile money) agent/shopkeeper in performing a transaction, the VIP often had to give the agent cash to deposit, ask for a specific amount of cash to be withdrawn and/or share some highly sensitive information (i.e. their account number).

The defining element of dependent interactions was trust. Although dependent interactions appear similar to supported interactions, they differ in two important aspects. First, supported interactions only occurred with individuals who were already within the VIP's social circles, whilst dependent interactions happened specifically with shopkeepers and M-Pesa agents outside of this social circle. Second, participants reported feeling they had little control over the situation during dependent interactions, whereas this did not occur during supported interactions.

All participants had built relationships with one specific MPesa agent that they would go to in order to complete essential mobile banking transactions. The agents of these trusted shops are relied upon. Often the VIP would assess how they were treated, then build up trust by becoming a committed and loyal a customer. VIPs had honed their abilities to assess which people were trustworthy through trial and error. This trust was built up "little by little until the time that my instinct tells me that you are a good person" [P06, Interview]. Most participants were very cautious about deciding which shopkeeper they would trust, and this was often motivated by the fact that they had been defrauded or they have had items stolen from them before.

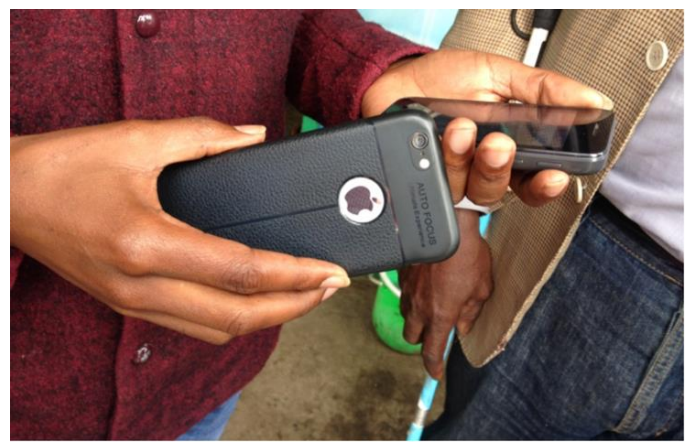

Figure 4: An example dependent interaction - an M-Pesa agent helps a participant perform financial transactions by entering relevant data on the phone.

\section{STUDY 2: FUTURE VISIONS}

In the co-design exercises participants were asked to describe future scenarios in which technology enabled a visually impaired child who would live their life in Kibera to interact with the world in whichever way they wanted. 
The results were a series of imaginative stories in which our co-designers envisioned that generations of the future would not be held back by a lack of sight. Instead, the built environment would support the needs of VIPs and technology such as "advanced talking white canes" and "talking traffic lights and signage" would enable their characters to progress, be independent and give back to the community. Co-designers believed that PWDs can achieve great things with the right technology available - and with the support of others. Social acceptance would bring success, which in turn would be celebrated by their community. Therefore, independent interactions were a result of a supportive community.

The society described provided VIPs with the support they needed to thrive, and the children of the future became world-renowned doctors, computer engineers and pilots because they had both advanced technology and supportive social systems. The mobile phone was not explicitly mentioned as part of this future. Instead participants designed an array of connected technologies (see Figure 3). Interestingly, nearly all of these technologies exist, and nearly all solutions focused on navigation. Independent navigation is key to developing social interactions within people's lived environments [46]. The importance of navigation was clearly evident in study 2 , which makes its complete omission in study 1 all the more poignant (it was identified by its omission as a restricted interactions).

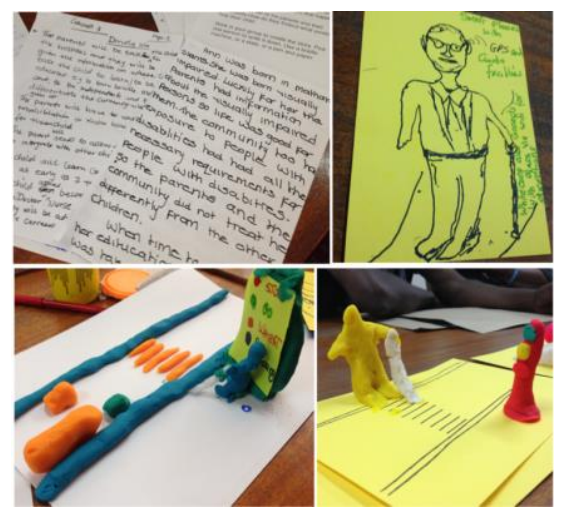

Figure 3: Stories and technology solutions developed by participants during the co-design workshop. From top left clockwise: Stories from the future, GPS-enabled talking white cane and two Barra Barras (Zebra crossings).

We will now present the results of the imagined futures under our emerging four interaction types.

\section{(Un)Restricted Interactions}

In people's vision of the future, VIP children were not restricted when interacting in society. This unrestricted access was possible due to social acceptance. In these new realities "stigmatization is limited" and VIPs are "high profile" [G4]. Therefore, there were no restricted interactions. Instead a new category - unrestricted interactions - emerged. Unrestricted interactions are characterized by external factors to the specific interactions with the technology. These external factors are in essence all part of social acceptance.

Social acceptance was made possible first by freely available information. For example, "The Government [has] created advanced information centres for each community" [G1], enabling "Parents to get all the information needed to send her [the child] to a good school" [G2]. These were all provided at no cost to the parents. This freedom of information had a trickle-down effect and allowed for "community [that was] was well informed on the rights for persons with VI" [G1]. All groups mentioned a "community that is well informed" as essential to the visions they described. It would appear this was the bedrock for all future interactions. It might also explain why there were no instances of dependent interactions reported in the visions of the future as people simply imagined a world of support not dependency.

None of the technologies suggested in the future lives of people in Kibera 'cured' the sight of the child, they were all very rooted in a community which was simply accepting.

\section{Supported Interactions}

Supported interactions were described in two directions. On the one hand assistive technologies, specifically in education supported the future VIP children to "excel academically and socially - even to University" [G4]. They were further supported by interactions with their teachers. This education then allowed the VIP, Bryan in this instance, to "get employed and sets up his own company and [becoming] well known in ICT' [G4]. Thus, in this imagined future there were opportunities for VIPs of the future to create technologies which in turn supported interactions in the community. Groups spoke of people being able to create "employment opportunities for others because of the way society has accepted him" [G4]; another child had grown up to "become independent and able to give back to the community she grew up in" [G3].

\section{Independent Interactions}

Independent interactions dominated much of the discussion and designs created by all 4 groups. There was a clear focus on navigation, which in study 1 was identified as a restricted interaction. Two groups focused on the creation of technology that was specifically designed to help VIPs cross busy roads creating: Traffic lights that let VIPs know when it is time to cross - so that they can do so independently and; a Barra Barra (Zebra crossing) with a blue button to indicate to waiting drivers that a PWD is crossing - so they would be more patient if the person needs a longer time to cross. A third group focused on the creation of talking smart white canes which were GPS enabled, to create more independent interactions. Participants also described the features of several ramps and pavements designed to allow VIPs to walk freely and safely in urban areas. An umbrella-hat for rainy days when using a white cane - it opens when the user presses a button on the hat and keeps them dry and they still have one hand free to guide their way - was also proposed. 
Although there was a focus on navigation, other ideas did emerge: a cooking pot that doesn't need gas or charcoal and cooked food by itself; and a cup with a sensor that beeps when the liquid reaches a certain threshold to prevent the VIP user from overfilling it and potentially burning themselves.

\section{DISCUSSION}

\section{The Social Network}

The social network of Kibera is rich. Ultimately, we found mobile phone use was enabled by and for social networks. This points to a unique dualism; mobile phones have limited value without a social network, and additionally, each independent interaction made by users was towards engagement in their community (e.g. reaching out to family and friends). This dualism is not unique to informal settlements. Previous work has found collaboration between family members, co-workers and fellow activists was enabled by access to and through technology [3]. Similarly, AT has been found to both hinder and help the everyday work-dynamics between VIPs and non-VIPs [7]. Our study uncovered new dimensions of the social network. We show how different kinds of social bonds between VIPs and their technology helper gave rise to different types of interaction that might be more or less acceptable to the VIP.

Supported interactions were possible due to the close proximity and open living conditions found in Kibera. These result in community dynamics where physically calling out to a neighbor from your abode results in an instant and helpful response. This idea of interactions taking place on the 'doorstep' has been found previously [51]. However, needing social support in order to access technology often places an invisible burden on the VIP making everyday life more complicated [8]. This was especially true in our study within dependent interactions, when people found they were unable to top-up their phones or withdraw money from their M-Pesa account when their trusted agent was not available. Supported interactions where made possible by the physical environment, however, the same environment also created restricted interactions. The unstructured nature of the physical space when combined with a lack of accessible smartphone technology contributed to a lack of mobileenabled navigation opportunities which in turn restricted social interactions. One aim of mobile phone use is to enable better access to the lived environment [46]. Pal et al. [46] previously found that the lived environment of a person, which includes the physical infrastructure and transport system, is still challenging for VIPs to navigate independently. Our findings build on the findings of Pal et al. [46]. We offer additional evidence of the power of mobile to extend the accessibility of open spaces for VIPs to enhance inclusion. There is opportunity in the future for $\mathrm{HCI}$ researchers to explore how the social network can be leveraged to create new solutions for open spaces.

\section{The directionality of trust}

When examining the stories recalled by our participants, we found that trust was often the glue which held the technology support network together. This was in line with previous research which showed that trust is a foundation on which infrastructures beyond direct use operate [51,52]. The creation of social networks was bound up with decisions about whom could be trusted, and what they could be trusted with. Due to its inherent importance, participants have developed complex strategies which they used to establish and build trust which is a constant and evaluative process. In our study trust within supported interactions was implicit and encouraged through the social fabric of Kibera.

Dependent interactions however were more nuanced. In previous work trust in new socio-technical systems such as ridesharing has been shown to be built by the technology. For example, VIPs using ridesharing schemes in India have used the audio output of GPS-enabled location data to trust they are being taken to their destination by the driver [11]. In contrast we did not find technology as an enabler in building trust, though it was envisaged as such in future interactions (see later). In common with previous studies $[4,5,11,15]$ we found trust being built by recurring exchanges between service user and provider during dependent interactions. The rationale given by Brewer \& Kamerswaren [11] for engaging in such behavior from the point of view of the service provider can be likened to incentivized trust-building found by [2]. The service provider is incentivized to develop trust to ensure continued service, often with ridesharing and similar systems through a rating-based system. Within our study we saw a more nuanced concept of this relationship. Trust was initially tested through trial and error by our VIPs, who went through a process of constant evaluation of $\mathrm{M}$ Pesa agents and shopkeepers. This was unaided by an app or rating system, and whilst VIPs could ask sighted peers for advice, their visual impairment put them in a place of unique vulnerability which was disconnected from a sighted person's experience. For example, this was evident when viewing how much information was given to M-Pesa agents by the VIP smartphone user in comparison with non-VIP customers who needed to give no such information to the MPesa agent. Star stated that people make meanings based on their circumstances and in doing so these meanings are inscribed into peoples' judgements [62], or in other words, our participants needed to trust M-Pesa agents - and so they did, until and if they realized they couldn't. One of the most uncomfortable elements of dependent interactions is the fact that the risk sits only on the side of the VIP. Trust is usually a mutual relationship [81:1] and it feels unbalanced to have to trust someone that you don't know and that doesn't necessarily trust you in return.

We found the combination of limited choices of technology and a lack of knowledge of current phone features led an increase in dependent interactions when needing to use money-transactions services through the M-Pesa system. However, the subsequent dependent interactions built a strength of relationship between user and service provider which could be characterized by a level of devotion to the service user. For example - One M-Pesa agent aborted a trip 
into Nairobi to make himself available for one participant and several spoke of the other people with disabilities of low digital skills that they also help. These interactions appear to be driven from a different place to the more traditional incentivized trust-building activities found in previous mobile money studies [21,22].

\section{The illusive 'blind phone'}

Participants showed a desire to adopt new technologies which they believed would improve the quality of their lives, but which they assumed were out of reach. These included a 'phone for the blind' and speaking computers. Unlike the VIPs in Pal et al.'s study which included several African countries [43], we found no one using screen reading software on their feature phones. Despite the appetite for it there was a lack of clarity about what a 'phone for the blind' actually was. However, there was a clear perception that it was out of reach financially to our participants. When asked people would describe the fact the phone would talk, something their current handset was capable of. It would appear that people, unwittingly were holding the blind phone they desired.

The one smartphone user in our study was aware of using what he believed was a phone for the blind. In keeping with previous research [24] this phone was given to him via a charity. When using this phone, we observed accessibility and usability issues with the design of the M-Pesa banking service - such as the inability to enter account IDs and amounts. This supports the findings of Wyche et al. [77], and drove the need for dependent interactions. Like Pal et al. [45] our smartphone user made the switch from a feature phone despite awareness of the usability challenges it would present. Mobile banking was particularly problematic. This is worrying and chimes with the view that technology can act as an amplifier of the attitudes within a society [66]; in this case inaccessible technology is amplifying exclusion.

\section{Future interactions}

Independent use of technology is often a driving factor for the design of technology for people with disabilities $[13,25,60]$. Future interactions described by our participants build on the idea of independence described by Kameswaran et al [30]. Independence is seen as not only what you can do for yourself, but also what you can do for others and peoples' confidence that you will be able to do these actions reliably. Shinohara \& Wobbrock [58] highlighted how accessible technology can empower people with disabilities in demonstrating their skills and enable them to support others in completing small and big tasks. This was reflected in the newly imagined futures of our VIPs where we saw not only technologies which would enable independence (e.g. GPSenabled white cane) but also support them in achieving prominent roles within society. VIPs envisioned that the children of the future would fulfill roles such as teachers, medical doctors and pilots, figures that are perceived as dependable and skillful. Furthermore, these roles also enable the person with visual impairment to demonstrably give to society, rather than simply be in receipt of help. In doing so technology was an enabler not only in helping people do tasks independently but also demonstrated their ability to be a competent member of society [20,30]. The new technologies were all socially acceptable, many of which were built into mainstream technology such as intelligent road crossings, others were more akin to traditional assistive products such as the talking white cane. However, all were socially accepted not only by the PWD but also the people with whom they interacted. This finding extends the work of Shinohara \& Wobbrock [57] who identified the need for AT to be functionally and socially acceptable to ensure access and independence for PWDs within the work and home setting of a high-income country.

\section{LIMITATIONS}

The major limitation for the current study is the small sample size. We also conducted the current study over two weeks, making opportunities for capacity development of the local team limited. However, this is the start of a much longer ongoing research process within which we hope to further develop and refine our approach.

\section{CONCLUSION}

The social networks of VIPs living in Kibera were fundamentally important in shaping both how and why VIPs used their mobile phones. We have presented two studies; a series of interviews and observations, followed by a codesign workshop that looked at the way VIPs used their mobile phones and how this use was shaped by, and in turn shaped, their social networks. Results from the first study show the social networks in Kibera for VIPs are comprised of four types of interaction with their mobile phone. VIPs often used their mobile themselves to reach out to their friends and families (direct interactions). When support was needed VIPs looked for help among close relations, neighbors and trusted technology advisors (supported interactions). To access financial services through the mobile phones, VIPs had to rely on shopkeepers and mobile agents (dependent interactions), sharing private information and handing over cash which required full trust and involved an element of risk for participants. The inaccessibility of certain mobile services due to cost, the lack of digital literacy of the VIP and the limited capabilities of the mobile phone, restricted certain interactions (restricted interactions). Our second study demonstrated future interactions would result in full inclusion of VIPs, through unrestricted interactions allowing VIPs to be valued members of society.

\section{ACKNOWLEDGMENTS}

We would like to thank all of the study participants for their valuable time and insights. Additionally, we are immensely grateful to the Kilimanjaro Blind Trust (www.kilimanjaroblindtrust.org) for their support in study recruitment and use of facilities. The research in this paper was made possible by funding from the UK Department for International Development through the AT2030 Programme (www.AT2030.org) which is led by the Global Disability Innovation Hub (www.DisabilityInnovation.com). 


\section{REFERENCES}

[1] Ilias Apostolopoulos, Navid Fallah, Eelke Folmer, and Kostas E. Bekris. 2014. Integrated Online Localization and Navigation for People with Visual Impairments Using Smart Phones. ACM Trans Interact Intell Syst 3, 4 (January 2014), 21:1-21:28. DOI:https://doi.org/10.1145/2499669

[2] Shiri Azenkot, Richard E. Ladner, and Jacob O. Wobbrock. 2011. Smartphone Haptic Feedback for Nonvisual Wayfinding. In The Proceedings of the 13th International ACM SIGACCESS Conference on Computers and Accessibility (ASSETS '11), ACM, New York, NY, USA, 281-282. DOI:https://doi.org/10.1145/2049536.2049607

[3] Cynthia L. Bennett, Erin Brady, and Stacy M. Branham. 2018. Interdependence As a Frame for Assistive Technology Research and Design. In Proceedings of the 20th International ACM SIGACCESS Conference on Computers and Accessibility (ASSETS '18), ACM, New York, NY, USA, $161-173$ DOI:https://doi.org/10.1145/3234695.3236348

[4] Timothy Bickmore and Justine Cassell. 2001. Relational Agents: A Model and Implementation of Building User Trust. In Proceedings of the SIGCHI Conference on Human Factors in Computing Systems (CHI '01), ACM, New York, NY, USA, 396-403. DOI:https://doi.org/10.1145/365024.365304

[5] Timothy W. Bickmore and Rosalind W. Picard. 2005. Establishing and Maintaining Long-term Humancomputer Relationships. ACM Trans Comput-Hum Interact 12, 2 (June 2005), 293-327. DOI:https://doi.org/10.1145/1067860.1067867

[6] Julia Bird, Piero Montebruno, and Tanner Regan. 2017. Life in a slum: understanding living conditions in Nairobi's slums across time and space. Oxf. Rev. Econ. Policy 33, 3 (2017), 496-520.

[7] Stacy M. Branham and Shaun K. Kane. 2015. Collaborative Accessibility: How Blind and Sighted Companions Co-Create Accessible Home Spaces. In Proceedings of the 33rd Annual ACM Conference on Human Factors in Computing Systems (CHI '15), ACM, New York, NY, USA, 2373-2382. DOI:https://doi.org/10.1145/2702123.2702511

[8] Stacy M. Branham and Shaun K. Kane. 2015. The Invisible Work of Accessibility: How Blind Employees Manage Accessibility in Mixed-Ability Workplaces. In Proceedings of the 17th International ACM SIGACCESS Conference on Computers \&\#38; Accessibility (ASSETS '15), ACM, New York, NY, USA, $163-171$. DOI:https://doi.org/10.1145/2700648.2809864

[9] Virginia Braun and Victoria Clarke. 2006. Using thematic analysis in psychology. Qual. Res. Psychol. 3, 2 (January 2006), 77-101. DOI:https://doi.org/10.1191/1478088706qp063oa
[10] Margot Brereton, Paul Roe, Ronald Schroeter, and Anita Lee Hong. 2014. Beyond Ethnography: Engagement and Reciprocity As Foundations for Design Research out Here. In Proceedings of the SIGCHI Conference on Human Factors in Computing Systems (CHI '14), ACM, New York, NY, USA, 1183-1186.

DOI:https://doi.org/10.1145/2556288.2557374

[11] Robin N. Brewer and Vaishnav Kameswaran. 2019. Understanding Trust, Transportation, and Accessibility Through Ridesharing. In Proceedings of the 2019 CHI Conference on Human Factors in Computing Systems (CHI '19), ACM, New York, NY, USA, 195:1-195:11. DOI:https://doi.org/10.1145/3290605.3300425

[12] Maria Claudia Buzzi, Marina Buzzi, Barbara Leporini, and Amaury Trujillo. 2014. Designing a Text Entry Multimodal Keypad for Blind Users of Touchscreen Mobile Phones. In Proceedings of the 16th International ACM SIGACCESS Conference on Computers \& Accessibility (ASSETS '14), ACM, New York, NY, USA, 131-136. DOI:https://doi.org/10.1145/2661334.2661354

[13] Clare Carroll, Catherine Chiodo, Adena Xin Lin, Meg Nidever, and Jayanth Prathipati. 2017. Robin: Enabling Independence For Individuals With Cognitive Disabilities Using Voice Assistive Technology. In Proceedings of the 2017 CHI Conference Extended Abstracts on Human Factors in Computing Systems (CHI EA '17), ACM, New York, NY, USA, 46-53. DOI:https://doi.org/10.1145/3027063.3049266

[14] Marshini Chetty and Rebecca E. Grinter. 2007. HCI4D: Hci Challenges in the Global South. In CHI '07 Extended Abstracts on Human Factors in Computing Systems (CHI EA '07), ACM, New York, NY, USA, 2327-2332. DOI:https://doi.org/10.1145/1240866.1241002

[15] Tawanna R. Dillahunt, Vaishnav Kameswaran, Linfeng Li, and Tanya Rosenblat. 2017. Uncovering the Values and Constraints of Real-time Ridesharing for Low-resource Populations. In Proceedings of the 2017 CHI Conference on Human Factors in Computing Systems (CHI '17), ACM, New York, NY, USA, 2757-2769. DOI:https://doi.org/10.1145/3025453.3025470

[16] Kevin Doughty. 2011. SPAs (smart phone applications) - a new form of assistive technology. $J$. Assist. Technol. (June 2011). DOI:https://doi.org/10.1108/17549451111149296

[17] Anthony Dunne and Fiona Raby. 2013. Speculative Everything: Design, Fiction, and Social Dreaming. MIT Press.

[18] Jennifer Fereday and Eimear Muir-Cochrane. 2006. Demonstrating rigor using thematic analysis: A hybrid approach of inductive and deductive coding and theme 
development. Int. J. Qual. Methods 5, 1 (2006), 8092.

[19] Emiliano Firmino and Mauro Teófilo. 2013. Visually impaired navigation assistant for emerging market using tactile floor, feature phone and audio descriptions. ACM, 20. DOI:https://doi.org/10.1145/2537052.2537072

[20] Harold Garfinkel. 1967. Studies in ethnomethodology. Englewood cliffs. Prentice-Hall (1967).

[21] Ishita Ghosh. 2013. The agent in a transformational mbanking ecosystem: interface or intermediary? In Proceedings of the Sixth International Conference on Information and Communications Technologies and Development: Notes-Volume 2, ACM, 33-36.

[22] Ishita Ghosh. 2016. Contextualizing Intermediated Use in the Developing World: Findings from India \& Ghana. In Proceedings of the 2016 CHI Conference on Human Factors in Computing Systems (CHI '16), ACM, New York, NY, USA, 355-359. DOI:https://doi.org/10.1145/2858036.2858594

[23] Jonathan Grudin. 1990. The Computer Reaches out: The Historical Continuity of Interface Design. In Proceedings of the SIGCHI Conference on Human Factors in Computing Systems (CHI '90), ACM, New York, NY, USA, 261-268. DOI:https://doi.org/10.1145/97243.97284

[24] GSMA. 2019. Understanding the mobile disability gapInsights on mobile phone access and usage by persons with disabilities in Kenya and Bangladesh. Retrieved from https://www.gsma.com/mobilefordevelopment/wpcontent/uploads/2019/12/GSMA_Understanding-themobile-disability-gap_116pg_Accessible.pdf

[25] João Guerreiro, Dragan Ahmetovic, Daisuke Sato, Kris Kitani, and Chieko Asakawa. 2019. Airport Accessibility and Navigation Assistance for People with Visual Impairments. In Proceedings of the 2019 CHI Conference on Human Factors in Computing Systems (CHI '19), ACM, New York, NY, USA, 16:116:14. DOI:https://doi.org/10.1145/3290605.3300246

[26] Lilit Hakobyan, Jo Lumsden, Dympna O'Sullivan, and Hannah Bartlett. 2013. Mobile assistive technologies for the visually impaired. Surv. Ophthalmol. 58, 6 (December 2013), 513-528. DOI:https://doi.org/10.1016/j.survophthal.2012.10.00 4

[27] Catherine Holloway. 2019. Disability interaction (DIX): A manifesto. ACM Interact. 26, 2 (February 2019) (2019), 44-49. DOI:https://doi.org/10.1145/3310322

[28] Catherine Holloway, Victoria Austin, Giulia Barbareschi, and Ramos. 2018. Scoping research Report on Assistive Technology. On the road for universal assistive technology coverage. Prepared by the GDI Hub \& partners for the UK Department for International Development. Global Disability Innvoation Hub.
[29] Hernisa Kacorri, Kris M. Kitani, Jeffrey P. Bigham, and Chieko Asakawa. 2017. People with Visual Impairment Training Personal Object Recognizers: Feasibility and Challenges. In Proceedings of the 2017 CHI Conference on Human Factors in Computing Systems (CHI '17), ACM, New York, NY, USA, 5839-5849.

DOI:https://doi.org/10.1145/3025453.3025899

[30] Vaishnav Kameswaran, Jatin Gupta, Joyojeet Pal, Sile O’Modhrain, Tiffany C. Veinot, Robin Brewer, Aakanksha Parameshwar, Vidhya Y, and Jacki O’Neill. 2018. "We Can Go Anywhere": Understanding Independence Through a Case Study of Ride-hailing Use by People with Visual Impairments in Metropolitan India. Proc ACM Hum-Comput Interact 2, CSCW (November 2018), 85:1-85:24. DOI:https://doi.org/10.1145/3274354

[31] Shaun K. Kane, Chandrika Jayant, Jacob O. Wobbrock, and Richard E. Ladner. 2009. Freedom to Roam: A Study of Mobile Device Adoption and Accessibility for People with Visual and Motor Disabilities. In Proceedings of the 11th International ACM SIGACCESS Conference on Computers and Accessibility (Assets '09), ACM, New York, NY, USA, $115-122$. DOI:https://doi.org/10.1145/1639642.1639663

[32] Seita Kayukawa, Keita Higuchi, João Guerreiro, Shigeo Morishima, Yoichi Sato, Kris Kitani, and Chieko Asakawa. 2019. BBeep: A Sonic Collision Avoidance System for Blind Travellers and Nearby Pedestrians. In Proceedings of the 2019 CHI Conference on Human Factors in Computing Systems (CHI '19), ACM, New York, NY, USA, 52:1-52:12. DOI:https://doi.org/10.1145/3290605.3300282

[33] Faith N. Kibere. 2016. The paradox of mobility in the Kenyan ICT ecosystem: An ethnographic case of how the youth in Kibera slum use and appropriate the mobile phone and the mobile internet. Inf. Technol. Dev. 22, sup1 (2016), 47-67.

[34] Frank Chun Yat Li, David Dearman, and Khai N. Truong. 2010. Leveraging Proprioception to Make Mobile Phones More Accessible to Users with Visual Impairments. In Proceedings of the 12th International ACM SIGACCESS Conference on Computers and Accessibility (ASSETS '10), ACM, New York, NY, USA, $187-194$. DOI:https://doi.org/10.1145/1878803.1878837

[35] Theresa Lorenzo. 2003. No African renaissance without disabled women: a communal approach to human development in Cape Town South Africa. Disabil. Soc. 18, 6 (October 2003), 759-778. DOI:https://doi.org/10.1080/0968759032000119505

[36] Theresa Lorenzo. 2008. "We are also travellers": An action story about disabled women mobilising for an accessible public transport system in Khayelitsha and Nyanga, Cape Metropole, South Africa. South Afr. J. Occup. Ther. 38, 1 (2008), 32-40. 
[37] Lauren R. Milne, Cynthia L. Bennett, and Richard E. Ladner. 2013. VBGhost: A Braille-based Educational Smartphone Game for Children. In Proceedings of the 15th International ACM SIGACCESS Conference on Computers and Accessibility (ASSETS '13), ACM, New York, NY, USA, 75:1-75:2. DOI:https://doi.org/10.1145/2513383.2513396

[38] Maghboeba Mosavel, Christian Simon, Debbie van Stade, and Mara Buchbinder. 2005. Community-based participatory research (CBPR) in South Africa: Engaging multiple constituents to shape the research question. Soc. Sci. Med. 61, 12 (December 2005), 2577-2587.

DOI:https://doi.org/10.1016/j.socscimed.2005.04.041

[39] National Coordinating Agency for Population and Development. 2008. Kenya - National Survey for Persons with Disabilities 2008. Retrieved September 20, 2019 from http://www.ilo.org/surveydata/index.php/catalog/927

[40] L. Van Niekerk, T. Lorenzo, and P. Mdlokolo. 2006. Understanding partnerships in developing disabled entrepreneurs through participatory action research. Disabil. Rehabil. 28, 5 (January 2006), 323-331. DOI:https://doi.org/10.1080/09638280500166425

[41] Nora Groce and Maria Kett. 2013. The Disability and Development Gap. Retrieved from http://www.ucl.ac.uk/leonard-cheshire-

research/research/publications/documents/workingpapers/wp-21.pdf

[42] 1615 L. St NW, Suite 800Washington, and DC 20036USA202-419-4300｜ Main202-857-8562 | Fax202-419-4372 | Media Inquiries. 2018. Social Media Use Continues to Rise in Developing Countries. Pew Research Center's Global Attitudes Project. Retrieved September 20, 2019 from https://www.pewresearch.org/global/2018/06/19/soci al-media-use-continues-to-rise-in-developingcountries-but-plateaus-across-developed-ones/

[43] Joyojeet Pal, Priyank Chandra, Terence O’Neill, Maura Youngman, Jasmine Jones, Ji Hye Song, William Strayer, and Ludmila Ferrari. 2016. An Accessibility Infrastructure for the Global South. In Proceedings of the Eighth International Conference on Information and Communication Technologies and Development (ICTD '16), ACM, New York, NY, USA, 24:1-24:11. DOI:https://doi.org/10.1145/2909609.2909666

[44] Joyojeet Pal, Manas Pradhan, Mihir Shah, and Rakesh Babu. 2011. Assistive Technology for Visionimpairments: Anagenda for the ICTD Community. In Proceedings of the 20th International Conference Companion on World Wide Web (WWW'11), ACM, New York, NY, USA, 513-522. DOI:https://doi.org/10.1145/1963192.1963365

[45] Joyojeet Pal, Anandhi Viswanathan, Priyank Chandra, Anisha Nazareth, Vaishnav Kameswaran, Hariharan Subramonyam, Aditya Johri, Mark S. Ackerman, and
Sile O’Modhrain. 2017. Agency in Assistive Technology Adoption: Visual Impairment and Smartphone Use in Bangalore. In Proceedings of the 2017 CHI Conference on Human Factors in Computing Systems (CHI '17), ACM, New York, NY, USA, 5929-5940.

DOI:https://doi.org/10.1145/3025453.3025895

[46] Joyojeet Pal, Anandhi Viswanathan, and Ji-Hye Song. 2016. Smartphone Adoption Drivers and Challenges in Urban Living: Cases from Seoul and Bangalore. In Proceedings of the 8th Indian Conference on Human Computer Interaction (IHCI '16), ACM, New York, NY, USA, 24-34. DOI:https://doi.org/10.1145/3014362.3014364

[47] Anicia N. Peters, Heike Winschiers-Theophilus, Kagonya Awori, Nicola J. Bidwell, Edwin Blake, Arun Kumar, and Shilumbe Chivuno-Kuria. 2014. Collaborating with Communities in Africa: A Hitchhikers Guide. In Proceedings of the Extended Abstracts of the 32Nd Annual ACM Conference on Human Factors in Computing Systems (CHI EA '14), ACM, New York, NY, USA, 1969-1974. DOI:https://doi.org/10.1145/2559206.2581313

[48] André Rodrigues, Kyle Montague, Hugo Nicolau, and Tiago Guerreiro. 2015. Getting Smartphones to Talkback: Understanding the Smartphone Adoption Process of Blind Users. In Proceedings of the 17th International ACM SIGACCESS Conference on Computers \& Accessibility (ASSETS '15), ACM, New York, NY, USA, 23-32. DOI:https://doi.org/10.1145/2700648.2809842

[49] Yvonne Rogers, Liam Bannon, and Graham Button. 1994. Rethinking Theoretical Frameworks for HCI: Report on an INTERCHI '93 Workshop, Amsterdam, 24-25th April, 1993. SIGCHI Bull 26, 1 (January 1994), $28-30$. DOI:https://doi.org/10.1145/181526.181530

[50] Yvonne Rogers and Gary Marsden. 2013. Does he take sugar?: moving beyond the rhetoric of compassion. interactions 20, 4 (2013), 48-57.

[51] Nithya Sambasivan, Ed Cutrell, Kentaro Toyama, and Bonnie Nardi. 2010. Intermediated Technology Use in Developing Communities. In Proceedings of the SIGCHI Conference on Human Factors in Computing Systems (CHI '10), ACM, New York, NY, USA, 2583-2592.

DOI:https://doi.org/10.1145/1753326.1753718

[52] Nithya Sambasivan and Thomas Smyth. 2010. The Human Infrastructure of ICTD. In Proceedings of the 4th ACM/IEEE International Conference on Information and Communication Technologies and Development (ICTD '10), ACM, New York, NY, USA, $\quad 40: 1-40: 9$ DOI:https://doi.org/10.1145/2369220.2369258

[53] M. A. C. Schouten and R. W. Mathenge. 2010. Communal sanitation alternatives for slums: A case 
study of Kibera, Kenya. Phys. Chem. Earth Parts ABC 35, 13-14 (2010), 815-822.

[54] Amartya Sen. 2001. Development as Freedom (New Ed edition ed.). OUP Oxford, Oxford ; New York.

[55] Akbar S. Shaik, G. Hossain, and M. Yeasin. 2010. Design, development and performance evaluation of reconfigured mobile Android phone for people who are blind or visually impaired. ACM, 159-166. DOI:https://doi.org/10.1145/1878450.1878478

[56] Longfei Shangguan, Zheng Yang, Zimu Zhou, Xiaolong Zheng, Chenshu Wu, and Yunhao Liu. 2014. CrossNavi: Enabling Real-time Crossroad Navigation for the Blind with Commodity Phones. In Proceedings of the 2014 ACM International Joint Conference on Pervasive and Ubiquitous Computing (UbiComp '14), ACM, New York, NY, USA, 787-798. DOI:https://doi.org/10.1145/2632048.2632083

[57] Kristen Shinohara and Jacob O. Wobbrock. 2011. In the Shadow of Misperception: Assistive Technology Use and Social Interactions. In Proceedings of the SIGCHI Conference on Human Factors in Computing Systems (CHI '11), ACM, New York, NY, USA, 705714. DOI:https://doi.org/10.1145/1978942.1979044

[58] Kristen Shinohara and Jacob O. Wobbrock. 2016. Self-Conscious or Self-Confident? A Diary Study Conceptualizing the Social Accessibility of Assistive Technology. ACM Trans Access Comput 8, 2 (January 2016), $5: 1-5: 31$ DOI:https://doi.org/10.1145/2827857

[59] Louise Skilling and Colin Rogers. 2017. Crime prevention and coping mechanisms in neighbourhoods: insights from Kibera, Nairobi. Crime Prev. Community Saf. 19, 2 (2017), 103-121.

[60] Ji-Won Song and Sung-Ho Yang. 2010. Touch Your Way: Haptic Sight for Visually Impaired People to Walk with Independence. In CHI '10 Extended Abstracts on Human Factors in Computing Systems (CHI EA '10), ACM, New York, NY, USA, 33433348. DOI:https://doi.org/10.1145/1753846.1753982

[61] Fiona Ssozi-Mugarura, Thomas Reitmaier, Anja Venter, and Edwin Blake. 2016. Enough with "In-TheWild." In Proceedings of the First African Conference on Human Computer Interaction (AfriCHI'16), ACM, New York, NY, USA, 182-186. DOI:https://doi.org/10.1145/2998581.2998601

[62] Susan Leigh Star. 1999. The ethnography of infrastructure. Am. Behav. Sci. 43, 3 (1999), 377-391.

[63] Sue Stubbs. 1999. Engaging with difference: Soulsearching for a methodology in disability and development research. Disabil. Dev. (1999), 257-79.

[64] Jeromey B. Temple and Margaret Kelaher. 2018. Is disability exclusion associated with psychological distress? Australian evidence from a national crosssectional survey. BMJ Open 8, 5 (May 2018), e020829. DOI:https://doi.org/10.1136/bmjopen-2017020829
[65] Anja Thieme, Cynthia L. Bennett, Cecily Morrison, Edward Cutrell, and Alex S. Taylor. 2018. "I can do everything but see!" -- How People with Vision Impairments Negotiate their Abilities in Social Contexts. In Proceedings of the 2018 CHI Conference on Human Factors in Computing Systems, Association for Computing Machinery, Montreal QC, Canada, Paper 203. Retrieved from https://doi.org/10.1145/3173574.3173777

[66] Kentaro Toyama. 2011. Technology As Amplifier in International Development. In Proceedings of the 2011 iConference (iConference '11), ACM, New York, NY, USA, 75-82. DOI:https://doi.org/10.1145/1940761.1940772

[67] Kentaro Toyama. 2013. Reflections on HCI for Development. Interactions 20, 6 (November 2013), 64-67. DOI:https://doi.org/10.1145/2527298

[68] Ivan Turok and Jackie Borel-Saladin. 2018. The theory and reality of urban slums: Pathways-out-ofpoverty or cul-de-sacs? Urban Stud. 55, 4 (2018), 767-789.

[69] Anna Rius Ulldemolins, Van C. Lansingh, Laura Guisasola Valencia, Marissa J. Carter, and Kristen A. Eckert. 2012. Social inequalities in blindness and visual impairment: a review of social determinants. Indian J. Ophthalmol. 60, 5 (October 2012), 368-375. DOI:https://doi.org/10.4103/0301-4738.100529

[70] Aditya Vashistha, Edward Cutrell, Nicola Dell, and Richard Anderson. 2015. Social Media Platforms for Low-Income Blind People in India. In Proceedings of the 17th International ACM SIGACCESS Conference on Computers \& Accessibility (ASSETS '15), ACM, New York, NY, USA, 259-272. DOI:https://doi.org/10.1145/2700648.2809858

[71] Elin Wihlborg and Per-Olof Hansson. 2011. Internet café as a supportive educational arena: a case study from the urban slum of Kibera, Nairobi, Kenya. In INTED 2011, International Technology, Education and Development Conference, 7-9 March, Valencia, Spain.

[72] R. Wiles, J. Prosser, A. Bagnoli, A. Clark, K. Davies, S. Holland, and E. Renold. 2008. Visual Ethics: Ethical Issues in Visual Research. (2008). Retrieved September 20, 2019 from https://www.research.manchester.ac.uk/portal/en/pub lications/visual-ethics-ethical-issues-in-visualresearch(17f0a3ff-c6b9-4c19-a1fd4adf3e5da8cb)/export.html

[73] Jacob O. Wobbrock, Shaun K. Kane, Krzysztof Z. Gajos, Susumu Harada, and Jon Froehlich. 2011. Ability-Based Design: Concept, Principles and Examples. ACM Trans. Access. Comput. 3, 3 (April 2011), 1-27. DOI:https://doi.org/10.1145/1952383.1952384

[74] World Health Organisation. 2017. Improving access to assistive technology: report by the Director-General. 
Retrieved from

https://apps.who.int/iris/handle/10665/274140

[75] Susan Wyche. 2015. Exploring Mobile Phone and Social Media Use in a Nairobi Slum: A Case for Alternative Approaches to Design in ICTD. In Proceedings of the Seventh International Conference on Information and Communication Technologies and Development (ICTD '15), ACM, New York, NY, USA, $12: 1-12: 8$. DOI:https://doi.org/10.1145/2737856.2738019

[76] Susan P. Wyche, Andrea Forte, and Sarita Yardi Schoenebeck. 2013. Hustling Online: Understanding Consolidated Facebook Use in an Informal Settlement in Nairobi. In Proceedings of the SIGCHI Conference on Human Factors in Computing Systems (CHI '13), ACM, New York, NY, USA, 2823-2832. DOI:https://doi.org/10.1145/2470654.2481391

[77] Susan Wyche, Nightingale Simiyu, and Martha E. Othieno. 2016. Mobile phones as amplifiers of social inequality among rural Kenyan women. ACM Trans. Comput.-Hum. Interact. TOCHI 23, 3 (2016), 14.

[78] Kianoosh Zakerhaghighi, Mojtaba Khanian, and Nima Gheitarani. 2015. Subjective Quality of Life; Assessment of Residents of Informal Settlements in Iran (A Case Study of Hesar Imam Khomeini, Hamedan). Appl. Res. Qual. Life 10, 3 (September 2015), 419-434. DOI:https://doi.org/10.1007/s11482014-9320-8

[79] The Diffusion of IT in the Historical Context of Innovations from Developed Countries | SpringerLink. Retrieved September 20, 2019 from https://link.springer.com/article/10.1007/s11205-0119989-0

[80] Mobile Report 2019| Jumia NG. Retrieved September 20, 2019 from https://www.jumia.com.ng/mobilereport/

[81] Trust, assurance, and inequality: A rational choice model of mutual trust 1: The Journal of Mathematical Sociology: Vol 26, No 1-2. Retrieved September 20, 2019

from https://www.tandfonline.com/doi/abs/10.1080/00222 500210525 
